\title{
Estrogen Modulates the Visceromotor Reflex and Responses of Spinal Dorsal Horn Neurons to Colorectal Stimulation in the Rat
}

\author{
Yaping Ji, ${ }^{1,4}$ Anne Z. Murphy, ${ }^{2,3,4}$ and Richard J. Traub ${ }^{1,2,3,4}$ \\ Departments of ${ }^{1}$ Oral and Craniofacial Biological Sciences, Dental School and ${ }^{2}$ Anatomy and Neurobiology, Medical School, ${ }^{3}$ Program in Neuroscience, and \\ ${ }^{4}$ Research Center for Neuroendocrine Influences on Pain, University of Maryland, Baltimore, Maryland 21201
}

\begin{abstract}
Many gastrointestinal pain syndromes are more prevalent in women than men, suggesting a gonadal steroid influence. We characterized the effects of estrogen on two responses to colorectal distention (CRD) in the rat: the visceromotor reflex (vmr) and L6-S1 dorsal horn neuron activity (ABRUPT and SUSTAINED neurons). Ovariectomized rats were injected with estrogen, and responses to innocuous and noxious intensities of CRD were measured between $4 \mathrm{hr}$ and $14 \mathrm{~d}$ after injection and compared with ovariectomized and intact, cycling rats. Plasma estrogen levels were determined at each time point. Ovariectomy significantly decreased the magnitude of the vmr and ABRUPT neuron response to CRD compared with cycling rats. Four and $48 \mathrm{hr}$ after estrogen injection (10 $\mu \mathrm{g})$, the magnitude of the vmr and ABRUPT neuron response returned to the level or greater than that of cycling rats. All responses were comparable with ovariectomized rats by $7 \mathrm{~d}$. These results paralleled the plasma estrogen concentration. Fifty micrograms of estrogen did not further increase the magnitude of the vmr or neuronal response $48 \mathrm{hr}$ after estrogen but did extend the period of the increased ABRUPT neuron response to $14 \mathrm{~d}$. Estrogen did not affect the response of SUSTAINED neurons. In a separate experiment, the response to innocuous CRD was sensitized in estrogen-treated rats but not ovariectomized or cycling rats. The present data suggest that estrogen modulates the spinal cord processing and reflex responses to innocuous and noxious colorectal stimuli in female rats and may contribute to alterations in sensory processing associated with irritable bowel syndrome.
\end{abstract}

Key words: visceral pain; visceral hyperalgesia; gonadal steroids; nociception; estrogen; lumbosacral spinal cord; electrophysiology; irritable bowel syndrome; IBS

\section{Introduction}

A number of chronic pain syndromes are more prevalent in women compared with men, including irritable bowel syndrome (IBS), fibromyalgia, and temporomandibular disorders (Unruh, 1996; Berkley, 1997). In many cases, the severity of symptoms fluctuate with the menstrual cycle (LeResche et al., 1997; Dao et al., 1998; Kane et al., 1998; Dao and LeResche, 2000; Fillingim and Ness, 2000; Fillingim and Edwards, 2001), suggesting that gonadal steroid levels impact pain severity. For example, IBS is two to three times more prevalent in women than men, and it has been reported that symptoms can increase perimenstrually (Case and Reid, 1998; Moore et al., 1998; Toner and Akman, 2000). Pharmacological or surgical ablation of menses reportedly decreases the severity of symptoms (Prior et al., 1992; Mathias et al., 1994). Acute experimental pain studies in humans also report that threshold and tolerance to experimental pain is modulated across the menstrual cycle (for review, see Riley et al., 1998) or by hormone replacement therapy (Fillingim and Edwards, 2001).

Received 0ct. 21, 2002; revised Jan. 31, 2003; accepted Feb. 4, 2003

This work was supported by National Institutes of Health (NIH) Grants NS 37424 and P50 AR49555. The RIAs were conducted by the University of Virginia Core RIA facility, which is supported by the National Institute of Child Health and Human Development/NIH through Cooperative Agreement U54 HD28934 as part of the Specialized Cooperative Centers Program in Reproduction Research.

Correspondence should be addressed to Dr. Richard J. Traub, Department of Oral and Craniofacial Biological Sciences, Dental School, University of Maryland, 666 West Baltimore Street, Baltimore, MD 21201. E-mail: rjt001@dental.umaryland.edu.

Copyright $\odot 2003$ Society for Neuroscience $\quad$ 0270-6474/03/233908-08\$15.00/0
Whether the increasing severity of symptoms is attributable to elevated or depressed levels of a particular hormone or the cyclical variation of hormone levels across the menstrual cycle is not clear.

Evidence from animal research also suggests sex differences in visceral and somatic nociceptive processing, but the role of gonadal hormones is controversial. Several studies indicate a negative correlation between endogenous estrogen levels and pain threshold, with sensitivity increasing when estrogen levels are highest or just thereafter (proestrus and estrus). For example, the threshold to evoke a visceromotor reflex or pressor response to colorectal distention (CRD) or to activate uterine and vaginal primary afferents is lowest in proestrus (Robbins et al., 1992; Sapsed-Byrne et al., 1996; Holdcroft et al., 2000). Similar results were reported after exogenous steroid administration (Forman et al., 1989; Ratka and Simpkins, 1991; Kayser et al., 1996; Bradshaw et al., 2000; Bereiter, 2001).

However, results to the contrary have also been reported. For example, elevated estrogen levels reportedly increase thresholds to cutaneous stimuli (Martinez-Gomez et al., 1994) and decrease the percentage of escape responses to vaginal canal stimulation (Bradshaw et al., 1999) or uretal calculosis (Giamberardino et al., 1997). Furthermore, elevated estrogen and progesterone, as occurs during pregnancy, is antinociceptive (Gintzler and Bohan, 1990; Dawson-Basoa and Gintzler, 1998).

Previous studies examining the effects of gonadal hormones on colorectal sensitivity were conducted exclusively in anesthe- 
tized intact, cycling female animals. In these studies, response thresholds to colorectal stimulation were lowest in proestrusestrus when estrogen and progesterone levels are at their highest (Sapsed-Byrne et al., 1996; Holdcroft et al., 2000). However, the individual contribution of estrogen or progesterone to changes in colorectal sensitivity are not known. To examine the role of gonadal hormones on visceral sensory processing to innocuous and noxious colorectal stimuli, and identify a locus of action, we tested the effects of ovariectomy and estrogen replacement on two responses to colorectal distention: the visceromotor reflex (vmr) and dorsal horn neuron activity.

Parts of this work have been published previously in abstract form (Traub et al., 2002a; Ji and Traub, 2002b).

\section{Materials and Methods}

Animals. Adult female Sprague Dawley rats (210-275 gm; Harlan Sprague Dawley, Indianapolis, IN) were used in the present experiment. One group of rats was ovariectomized $(\mathrm{OVx})$ and tested $10-30 \mathrm{~d}$ after the surgery. The other groups were given a single subcutaneous injection of 1,10 , or $50 \mu \mathrm{g}$ of $17-\beta$-estradiol-3 benzoate dissolved in $100 \mu \mathrm{l}$ of safflower oil (estrogen) at least $10 \mathrm{~d}$ after ovariectomy and tested beginning $4 \mathrm{hr}, 48 \mathrm{hr}, 7 \mathrm{~d}$, or $14 \mathrm{~d}$ thereafter. Vehicle control animals were ovariectomized and injected with $100 \mu \mathrm{l}$ of safflower oil $48 \mathrm{hr}$ before testing. Intact, cycling female rats were also tested for comparison. All experimental procedures were approved by the University of Maryland Dental School Animal Care and Use Committee.

Visceromotor reflex. Rats were implanted with electromyogram (EMG) electrodes made from Teflon-coated 32 gauge stainless steel wire (Cooner Wire Company, Chatsworth, CA) in the lateral abdominal wall 3-7 d before the experiment (Traub et al., 2002b). On the day of the experiment, rats were briefly sedated with halothane to place a $5-7 \mathrm{~cm}$ balloon attached to Tygon tubing through the anus into the descending colon and rectum. The distal end of the balloon was at least $1 \mathrm{~cm}$ proximal to the external anal sphincter. Rats were loosely restrained and allowed $30 \mathrm{~min}$ to recover from the halothane. Colorectal distention was produced by inflating the distention balloon with air. The pressure was monitored and kept constant by a pressure controller-timing device (Bioengineering, University of Iowa, Iowa City, IA). Rats were distended 12 times to $80 \mathrm{mmHg}$ CRD to achieve a stable response after any sensitization (Ness and Gebhart, 1988). At least two (generally three) graded intensity stimulation trials (20,40, 60, and $80 \mathrm{mmHg}$ CRD, 20 sec each, 3 min interstimulus interval) were run to establish a stable baseline response. Each trial was preceded by a distention to 80 then $10 \mathrm{mmHg}$. The response was considered stable if there was $<20 \%$ variability between the last $80 \mathrm{mmHg}$ distention of the last two trials.

The EMG recordings were collected with a CED 1401plus and analyzed using Spike 2 for windows software (Cambridge Electronic Design, Cambridge, UK). The EMG was rectified, and the area under the curve (AUC) for the $20 \mathrm{sec}$ before distention was subtracted from the AUC during the $20 \mathrm{sec}$ distention. The data are expressed as mean \pm SEM. Data were analyzed using two-way ANOVA. $p<0.05$ was considered significant.

Sensitization to innocuous CRD. In a separate group of intact, ovariectomized and $50 \mu \mathrm{g}$ estrogen-treated rats, the vmr was measured during twelve $20 \mathrm{mmHg}$ distentions ( $20 \mathrm{sec}$ duration, $3 \mathrm{~min}$ interstimulus inter$\mathrm{val}$ ). These rats were not distended before testing the $20 \mathrm{mmHg}$ stimulus. Rats were subsequently used to measure colonic compliance (see below).

Recording from spinal dorsal horn neurons. Female rats $(n=51)$ were ovariectomized 10-30 d before recording. A single injection of estrogen (10 or $50 \mu \mathrm{g}$ ) was given $4 \mathrm{hr}, 48 \mathrm{hr}, 7 \mathrm{~d}$, or $14 \mathrm{~d}$ before recording. A separate group of rats were ovariectomized but not injected. Another group of rats remained intact. In one-half of these intact animals, the stage of the estrous cycle was determined by daily vaginal smears. Rats were examined for three $4 \mathrm{~d}$ cycles and tested during diestrus 1 or 2 . The remaining rats were intact, but the stage of the estrous cycle was not determined.

On the day of the experiment, the rat was anesthetized with pentobar- bital sodium (50 mg/kg, i.p). The left jugular vein was catheterized for continuous infusion of pentobarbital sodium at a rate of 5-10 $\mathrm{mg} \cdot \mathrm{kg}^{-1} \cdot \mathrm{hr}^{-1}$. The left carotid artery was catheterized for continuous arterial blood pressure monitoring and bolus drug administration (pancuronium bromide, $0.2 \mathrm{mg} \cdot \mathrm{kg}^{-1} \cdot \mathrm{hr}^{-1}$ ). A tracheal cannula was inserted for artificial ventilation (2.5-3 cc stroke volume, 75-80 strokes/ min; adjusted so the mean arterial blood pressure was maintained between 95 and $120 \mathrm{mmHg}$ ). The body temperature was kept within physiological limits $\left(36-38^{\circ} \mathrm{C}\right)$ with a heating pad and overhead lamp.

The rat was placed in a head holder and suspended with thoracic vertebral and ishial clamps, and the lower lumbar-upper sacral spinal cord was exposed by laminectomy of the L1-L2 vertebrae. The dura matter was carefully cut, and the spinal cord was bathed in warm paraffin oil. A distention balloon was placed in the descending colon-rectum.

Tungsten microelectrodes (1-2 M $\Omega$; Micro Probe, Potomac, MD) were used for extracellular single-unit recording in the L6-S1 spinal segments $0-1 \mathrm{~mm}$ lateral to midline, $500-1300 \mu \mathrm{m}$ ventral to spinal cord dorsum. Signals were amplified (model 1800 AC amplifier; A-M Systems, Carlsborg, WA) and passed through a dual time and voltage window discriminator (DDIS-1; BAK Electronics, Germantown, MD) to isolate a single unit. Data were collected with a CED micro1401 and Spike2 for Windows software on computer for online and offline analysis.

The search stimulus consisted of touch and brief light pinch with serrated forceps on the rump and back area around the tail, the genital area, and the pelvic belly. When a neuron responsive to the above stimuli was identified, the colon was distended for $10 \mathrm{sec}$ at $80 \mathrm{mmHg}$ to test whether the neuron was responsive to CRD. Cells showing excitatory responses to CRD were classified as having a short latency and abrupt cessation of response (ABRUPT neurons) or short latency and sustained response (SUSTAINED neurons) according to their onset latency and duration of response to CRD. After identifying an ABRUPT or SUSTAINED neuron, at least two graded intensity distention trials (20, 40, 60 , and $80 \mathrm{mmHg}$, each distention lasting for $20 \mathrm{sec}$ with a $3 \mathrm{~min}$ interstimulus interval) were run to establish a stable response of the neuron. All distention trials were preceded by a distention to $80 \mathrm{mmHg}$. The response to distention was quantified as the firing frequency for $20 \mathrm{sec}$ (ABRUPT neurons) or $40 \mathrm{sec}$ (SUSTAINED neurons) after the onset of distention minus spontaneous activity during the 20 or $40 \mathrm{sec}$ before distention. The data are expressed as mean \pm SEM. Data were analyzed using two-way ANOVA. $p<0.05$ was considered significant.

Analysis of plasma estrogen concentration. At the end of each experiment, 1-1.5 ml of atrial blood was collected to determine plasma estrogen concentrations. Samples were left at room temperature for $1 \mathrm{hr}$ to allow for clot formation and then centrifuged at $14,000 \mathrm{rpm}$ for $10 \mathrm{~min}$ at $24^{\circ} \mathrm{C}$. The serum was collected and stored at $-20^{\circ} \mathrm{C}$ until radioimmunoassays were performed. Radioimmunoassays were conducted at the University of Virginia Core Radioimmunoassay Facility (Charlottesville, VA). All samples were run in duplicate.

Measurement of colonic compliance. In awake animals, the pressure in the distention balloon was measured by increasing the volume in the distention balloon by $0.5 \mathrm{ml}$ increments between 0 and $8.5 \mathrm{ml}$. This was measured three times in each rat, and the mean pressure at each volume increment was used as the measure for that rat.

\section{Results}

\section{Level of plasma estrogen and colon compliance}

The plasma estrogen concentration was measured by radioimmunoassay (Fig. 1A). A low level of estrogen $(0-15 \mathrm{pg} / \mathrm{ml})$ was detected 10-30 d after ovariectomy. Estrogen administration (10 or $50 \mu \mathrm{g}$ ) significantly increased plasma estrogen levels by $7-10$ hr. Plasma estrogen levels remained significantly elevated at $48 \mathrm{hr}$ and returned to OVx levels by $7 \mathrm{~d}$.

Colonic compliance was measured in three ovariectomized rats and three rats treated with $50 \mu \mathrm{g}$ of estrogen for $48 \mathrm{hr}$. There was no difference in the compliance of the colon in the estrogentreated rats compared with the ovariectomized rats (repeatedmeasures two-Way ANOVA; $p=0.687$ ). The volume-pressure curves were identical (Fig. $1 B$ ). The linear relationship between 


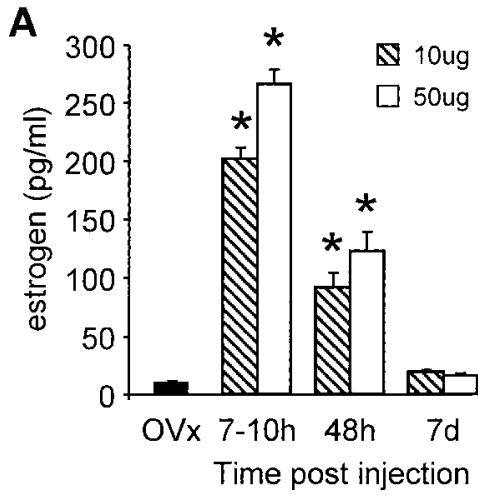

B

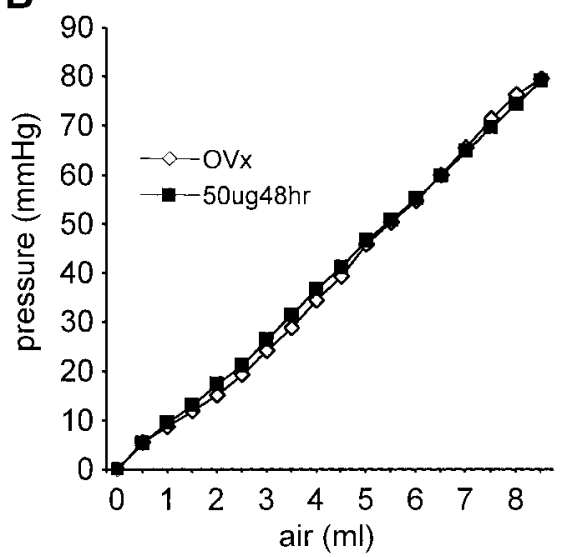

Figure 1. A, The plasma estrogen concentration from ovariectomized rats $(0 \mathrm{Vx})$ and 7-10 $\mathrm{hr}, 48 \mathrm{hr}$, and $7 \mathrm{~d}$ after a single injection of 10 or $50 \mu \mathrm{g}$ of estrogen to ovariectomized rats. Data are pooled from animals used in the vmr and single-unit studies. ${ }^{*} p<0.05$ compared with $0 \mathrm{Vx}$ or same dose of estrogen at $7 \mathrm{~d}$. Data were analyzed with Kruskal-Wallis one-way ANOVA on ranks, followed by Dunn's multiple comparison test. $B$, The volume-pressure relationship of the distention balloon in ovariectomized and estrogen-treated rats. The volume was increased in $0.5 \mathrm{ml}$ increments, and the corresponding pressure was recorded.

the volume and resulting pressure in both groups indicates that the balloon was compliant over this volume range, and the pressure readings reflected the pressure exerted by the colon wall on the balloon.

\section{Visceral motor reflex}

To test the hypothesis that gonadal hormones modulate colorectal sensitivity, the magnitude of the visceromotor reflex to innocuous and noxious intensities of CRD was measured. Compared with intact, cycling female rats $(n=14)$, ovariectomy $(n=26)$ significantly reduced the magnitude of the vmr over the range of distention intensities tested $(23 \%$ decrease at $80 \mathrm{mmHg}$; two-way ANOVA; $p<0.005$ ) (Fig. $2 A$ ).

We next examined the effect of exogenous estrogen administration on colorectal sensitivity. Ovariectomized rats received a single bolus injection of $10 \mu \mathrm{g}$ of estrogen, and the vmr to graded intensities of CRD was measured beginning $4 \mathrm{hr}(n=7), 48 \mathrm{hr}$ $(n=17)$, or $7 \mathrm{~d}(n=12)$ after injection. Compared with ovariectomized rats, estrogen produced a significant facilitation of the vmr (two-way ANOVA; $p<0.001$ ) (Fig. 2B). Measurements from the $4 \mathrm{hr}$ post-estrogen group were made between 4 and $7 \mathrm{hr}$ after injection. At this time point, the magnitude of the vmr was significantly increased ( $44 \%$ at $80 \mathrm{mmHg}$ ) compared with ovariectomized rats $(p=0.007)$. Forty-eight hours after estrogen injection, the magnitude of the vmr remained significantly elevated compared with ovariectomized rats $(p=0.002)$. At $7 \mathrm{~d}$ after
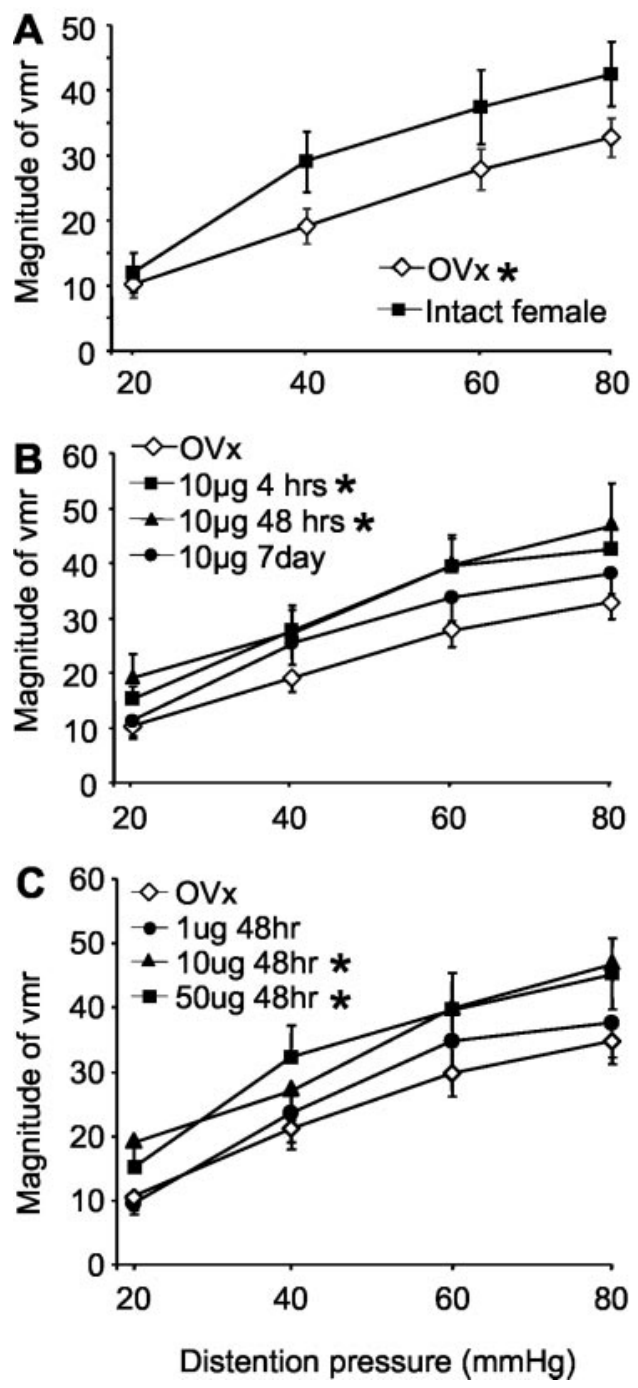

Figure 2. The magnitude of the vmr (mean area under the curve) after graded intensities of CRD. $A$, The magnitude of the vmr for intact female and ovariectomized rats. $B$, The effects of time after estrogen replacement on the magnitude of the vmr. $C$, The effects of dose of estrogen on the magnitude of the vmr. ${ }^{*} p<0.05$ compared with intact females in $A$ and $0 \mathrm{Vx}$ in $B$ and $C$.

estrogen injection, the magnitude of the vmr had returned to ovariectomized levels. The time course of estrogen-mediated facilitation of the vmr paralleled the changes in the plasma estrogen level (Fig. 1).

To determine whether the effect of estrogen was dose dependent, the vmr was measured in ovariectomized rats and $48 \mathrm{hr}$ after injection of safflower oil $(n=7), 1 \mu \mathrm{g}(n=6), 10 \mu \mathrm{g}$, or 50 $\mu \mathrm{g}(n=24)$ of estrogen. Ten and $50 \mu \mathrm{g}$ of estrogen significantly facilitated the vmr compared with ovariectomized rats (two-way ANOVA; $p<0.005$ ) (Fig. $2 C$ ), although there was no difference in the magnitude of the vmr between the 10 and $50 \mu \mathrm{g}$ doses $(p=$ $0.687)$. One microgram of estrogen had no effect on the magnitude of the vmr compared with ovariectomized rats $(p=0.650)$. Likewise, safflower oil alone was without effect $(p=0.854)$.

\section{Sensitization to repetitive innocuous CRD}

The vmr to repetitive noxious CRD in male rats is facilitated over the first 6-10 distentions (Ness and Gebhart, 1988); in contrast, repetitive innocuous distention does not produce sensitization (Traub et al., 2002b). Because estrogen increased sensitivity to graded intensities of CRD, we tested the hypothesis that estrogen 


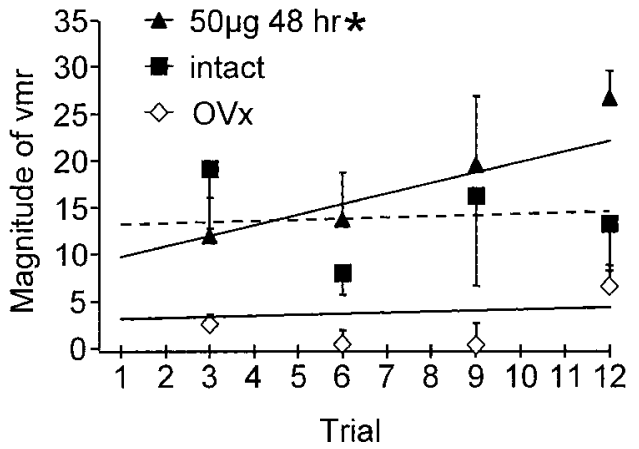

Figure 3. The magnitude of the vmr for the first 12 distentions at $20 \mathrm{mmHg}$. Every third data point is shown. Trend lines were determined from the 12 data points. ${ }^{*}$ indicates significant increase in slope versus OVx. $p<0.05$.

would increase colorectal sensitivity to repetitive innocuous (20 $\mathrm{mmHg}$ ) CRD in the absence of any noxious CRD. The rats were not distended before testing. Repetitive innocuous CRD failed to sensitize the vmr in intact female $(n=4)$ or ovariectomized rats $(n=7)$ (Fig. 3). No increase in the magnitude of the vmr over the first 12 distentions to $20 \mathrm{mmHg}$ (repeated-measures ANOVA; $p>0.8$ ) was noted, although the magnitude of the first distention had a tendency to be higher in the intact rats compared with the ovariectomized rats. In contrast, $48 \mathrm{hr}$ after estrogen $(50 \mu \mathrm{g} ; n=$ $7)$, there was a significant increase $(200 \%)$ in the magnitude of the vmr over 12 distentions (repeated-measures ANOVA; $p=$ 0.022 ). These results indicate that exogenous estrogen administration increased colorectal sensitivity to repetitive innocuous stimuli.

\section{Single-unit recording}

One interpretation of the vmr data are that the site of estrogen modulation of colorectal sensitivity to noxious and innocuous stimuli is in the spinal dorsal horn. Alternatively, estrogen could facilitate the motor component of the reflex without affecting the sensory component and/or modulate supraspinal processing or primary afferent input. To test the hypothesis that the modulation of the vmr was attributable to changes in dorsal horn activity, the response of dorsal horn neurons to graded intensities of CRD $(20,40,60$, and $80 \mathrm{mmHg})$ was examined and compared between ovariectomized ( $n=14$ neurons) and intact ( $n=22$ neurons) female rats. From the intact rats, 11 neurons were recorded from rats in diestrus, and 11 were recorded from rats in which the stage of the estrus cycle was not determined. There was no difference between these two groups, so the data were pooled. In ovariectomized rats, the magnitude of the response of ABRUPT neurons to CRD was significantly less than the response from intact female rats over the range of distention pressures tested (two-way ANOVA; $p<0.001$ ) (Fig. $4 A$ ). In contrast, no difference in the magnitude of the response of SUSTAINED neurons was noted between ovariectomized and cycling animals (two-way ANOVA; $p=0.782$ ) (Fig. $4 B$ ). These data suggest that steroidal modulation of dorsal horn neuronal responses to CRD is not universal but restricted to specific populations of neurons.

To determine whether the response of ABRUPT neurons is estrogen sensitive, the effect of estrogen administration was measured at several time points after injection. Four to $10 \mathrm{hr}$ after estrogen $(10 \mu \mathrm{g})$ injection, the magnitude of the response of ABRUPT neurons $(n=16)$ to CRD was significantly increased over the range of distention pressures compared with ovariectomized rats $(p<0.001)$ (Fig. $5 A)$. Forty-eight hours after a $10 \mu \mathrm{g}$
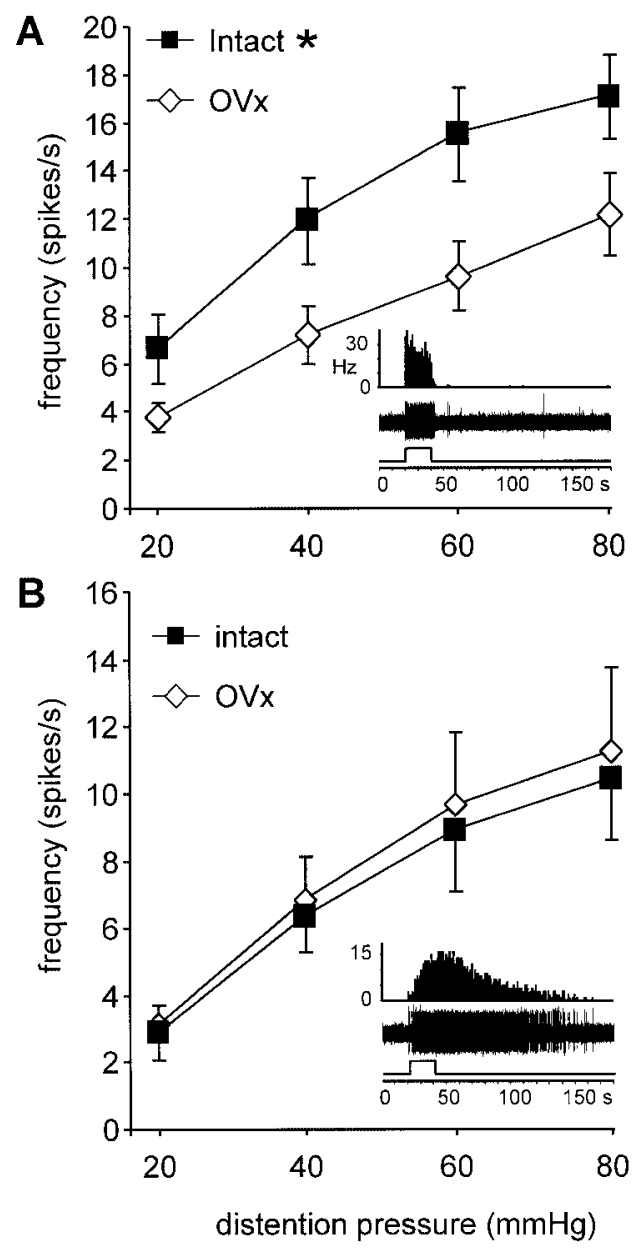

Figure 4. The mean magnitude of response of dorsal horn neurons to graded intensities of CRD. A, ABRUPT neurons. B, SUSTAINED neurons. Insets, Examples of a peristimulus time histogram (top trace) and spike discharge (middle trace) of an ABRUPT and a SUSTAINED neuron to $80 \mathrm{mmHg}$ CRD (bottom trace). * indicates significantly greater response compared with ovariectomized rats. $p<0.05$.

estrogen injection, the magnitude of the response of ABRUPT neurons $(n=17)$ was still significantly greater than that observed for ovariectomized rats. At this time point, the response was comparable with that in the intact cycling female rats. Seven days after estrogen, the response of ABRUPT neurons $(n=17)$ returned to the level of ovariectomized rats. The change in response of ABRUPT neurons to CRD paralleled the time course for changes in the plasma estrogen concentration. In addition, the time course for the increase in sensitivity of ABRUPT neurons to CRD paralleled the change in sensitivity observed in the vmr studies. In contrast, except for a transient increase 4-10 hr after injection, estrogen did not change the magnitude of the response of SUSTAINED neurons $(p=0.183$ ) (Fig. $5 C$ ).

The effects of $50 \mu \mathrm{g}$ of estrogen on the response of dorsal horn neurons was also examined (Fig. $5 B$ ). Although $50 \mu$ g of estrogen significantly increased the response of ABRUPT neurons similar to that observed after a $10 \mu \mathrm{g}$ injection (two-way ANOVA; $p<$ 0.001), the time course of the effects of the two doses differed. Four to $10 \mathrm{hr}$ after $50 \mu \mathrm{g}$ of estrogen, the magnitude of the response increased $(n=8)$ but did not peak until $7 \mathrm{~d}$ after injection $(n=16)$. Even $14 \mathrm{~d}$ after the estrogen injection $(n=9)$, the magnitude of the response was similar to that observed at $48 \mathrm{hr}$ $(n=10)$. Similar to the $10 \mu \mathrm{g}$ estrogen-treated rats, there was no 

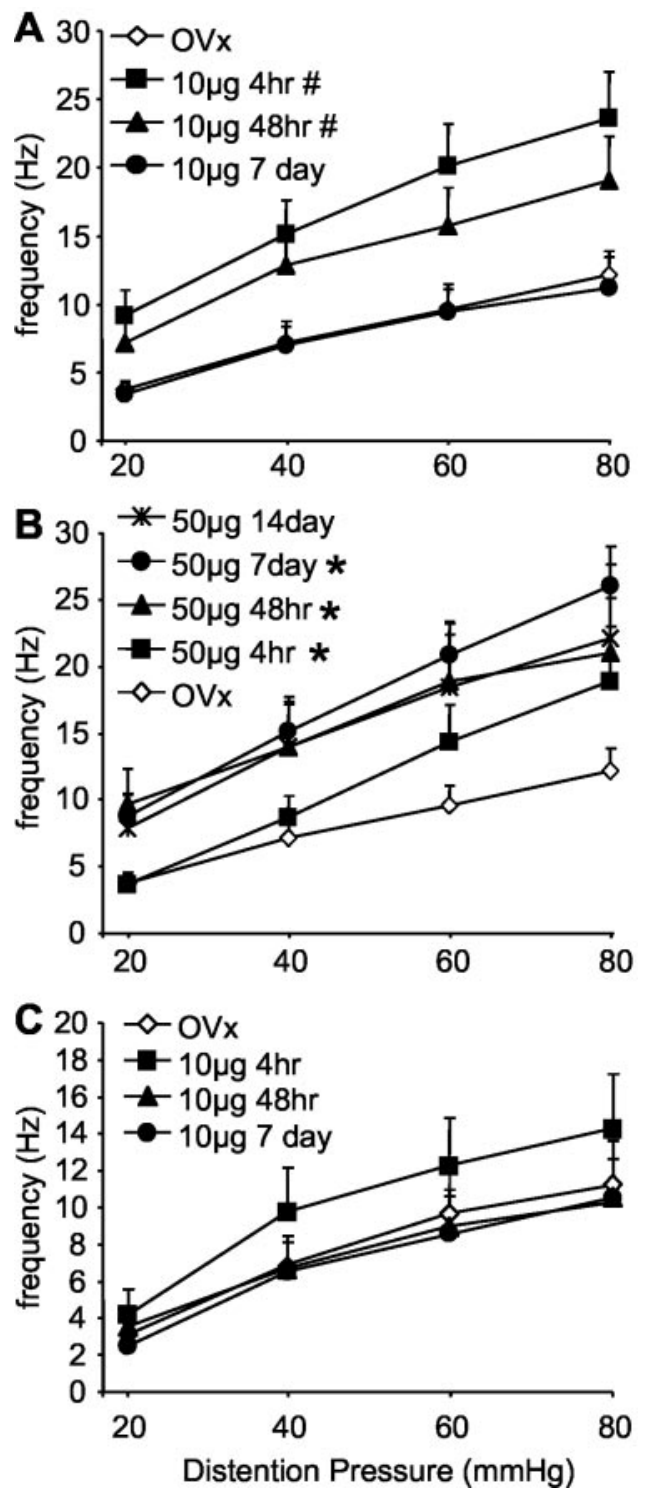

Figure 5. The mean magnitude of the response of ABRUPT $(A, B)$ or SUSTAINED $(C)$ dorsal horn neurons to graded intensities of CRD after $10 \mu \mathrm{g}(A, C)$ or $50 \mu \mathrm{g}(B)$ of estrogen. \#indicates significantly greater response compared with ovariectomized and $7 \mathrm{~d}$ post-estrogen rats. * indicates significantly greater response compared with ovariectomized rats. *\#p $<0.05$.

effect of $50 \mu \mathrm{g}$ of estrogen on the response of SUSTAINED neurons (data not shown).

\section{Response to somatic stimulation}

The response of CRD-responsive neurons to stimulation in their convergent somatic receptive field was also examined in some neurons. The response of neurons in ovariectomized rats to noxious pinch in the receptive field was $17.1 \pm 8.01 \mathrm{~Hz}(n=3)$; at 4 and $48 \mathrm{hr}$ after estrogen injection, the mean response rate was $23.5 \pm 5.2 \mathrm{~Hz}(n=11)$ and $25.3 \pm 10.5 \mathrm{~Hz}(n=7)$, respectively. Very few neurons were found to respond to somatic stimulation $7 \mathrm{~d}$ after estrogen injection, and the response to pinch in responsive neurons was relatively low $(7.82 \pm 4.17 \mathrm{~Hz} ; n=3)$. Overall, there was no significant difference among the four groups (oneway ANOVA; $p=0.603$ ).

\section{Discussion}

The present results demonstrate that the magnitude of the visceromotor reflex in awake rats and dorsal horn neuronal responses to CRD in anesthetized rats are significantly lower in ovariectomized rats compared with intact, cycling female rats. In addition, exogenous estrogen replacement produces recovery of these responses. Because estrogen receptors are expressed in dorsal horn neurons (Amandusson et al., 1995; Williams and Papka, 1996), the increase in the response of dorsal horn neurons induced by estrogen may underlie the observed visceral hypersensitivity.

\section{Is a single injection sufficient to study the effects of estrogen on sensory physiology?}

The plasma estrogen concentration after a single injection of 17$\beta$-estradiol mimics some characteristics of the natural fluctuation of estrogen in normal cycling female rats. During the proestrus phase in cycling rats, there is a rapid increase in the plasma estrogen concentration that peaks within $8-10 \mathrm{hr}$ of entering proestrus. During the subsequent $8-10 \mathrm{hr}$, the plasma estrogen decreases to a lower level as the rat enters the estrus phase (Freeman, 1994). The measurement of the plasma estrogen concentration from our experiment also showed a rapid increase and subsequent, albeit prolonged, decrease in the blood serum level after a single injection of 10 or $50 \mu \mathrm{g}$ of estrogen. This is consistent with previous reports of serum levels after estrogen replacement (Brown-Grant et al., 1970; Dupon and Kim, 1973; Butcher et al., 1974; Priest et al., 1995) and suggests that a single injection of estrogen mimics natural cycling and is appropriate for studying estrogen modulation of pain in the rat (Berglund et al., 1988).

\section{Estrogen modulates the reflex response to CRD}

The present study demonstrates that ovariectomy decreases sensitivity to CRD as measured by the visceromotor reflex. This suggests that gonadal hormones are important for the modulation of some aspects of viscerosensory processing. Previous studies have shown that the threshold for the visceromotor reflex in anesthetized rats varies as a function of the stage of the estrous cycle; response thresholds are lowest in proestrus when estrogen levels are highest (Sapsed-Byrne et al., 1996; Holdcroft et al., 2000). However, the contribution of progesterone and other associated steroids from intact gonads must also be taken into account. For example, progesterone is reportedly antinociceptive in some pain assays and may act to modulate the algesic effect of estrogen (Drury and Gold, 1978; Medina et al., 1993; DawsonBasoa and Gintzler, 1996; Ren et al., 2000). In the present study, we isolated the effects of estrogen by ovariectomy, followed by estrogen replacement. Our data show that estrogen replacement increases the magnitude of the vmr in as little as $4-6 \mathrm{hr}$ and maintains this high level of activity for at least $48 \mathrm{hr}$, paralleling changes in the plasma estrogen concentration.

It is interesting that a fivefold increase in the dose of estrogen did not result in any difference in the plasma estrogen concentration $48 \mathrm{hr}$ after injection, although both doses significantly increased the serum level compared with ovariectomy. Likewise, there was no difference in the magnitude of the vmr or neuronal responses between the 10 and $50 \mu$ groups, but both were greater than responses from ovariectomized rats. In contrast, $1 \mu \mathrm{g}$ of estrogen was not significantly different from ovariectomy or vehicle, suggesting there is a steep dose-response relationship between the plasma estrogen concentration and visceral sensitivity. However, at estrogen levels similar to those in normal cycling rats, the present data clearly indicate that estrogen increases colorectal sensitivity.

This conclusion is further supported by the sensitization experiment. The vmr in male rats is sensitized by repetitive noxious, but not innocuous, CRD (Ness and Gebhart, 1988; Traub et al., 
$2002 b)$. The present data show no sensitization to repetitive innocuous CRD in ovariectomized or cycling rats. However, after estrogen replacement, the vmr to innocuous CRD was sensitized. Similarly, repetitive colonic balloon distention induced rectal hyperalgesia in IBS patients but not control subjects (Munakata et al., 1997) (but see Ness et al., 1990), and thresholds to painful distention are lower in IBS patients compared with healthy controls (Ritchie, 1973; Mertz et al., 1995). Because IBS is most prevalent in premenopausal women, one hypothesis is that gonadal hormones increase sensitivity. The present data show that estrogen increases sensitivity to acute innocuous and noxious stimuli. It remains to be determined whether repetitive innocuous CRD in estrogen-treated rats becomes noxious with repeated stimulation, but the increase in sensitivity measured with the vmr suggests that estrogen, along with other factors, might contribute to the hypersensitivity associated with IBS.

\section{Estrogen modulates sensory processing in the spinal cord}

The results from the present in vivo electrophysiology experiment indicate that estrogen modulates the response of a subpopulation of CRD-responsive neurons in the dorsal horn, providing a mechanism for the behavioral changes observed in the vmr study. Although the vmr data demonstrate that estrogen modulates reflex responses to CRD, it does not identify the central site of action. Estrogen receptors are present in dorsal horn neurons (Amandusson et al., 1995, 1996; VanderHorst et al., 1997, 2001; Williams et al., 1997a,b; Papka et al., 2001), providing an anatomical basis for estrogen modulation of viscerosensory processing at the level of the dorsal horn. Furthermore, the time course of variation of the plasma estrogen concentration and neuronal activity are closely correlated, supporting a facilitatory effect of estrogen in colorectal sensory processing.

The activity of ABRUPT and SUSTAINED CRD-responsive dorsal horn neurons are differentially modulated by $\kappa$ - and $\mu$-opioid receptor agonists, as well as AMPA receptor antagonists (Ness and Gebhart, 1989; Al-Chaer et al., 1996; Ji and Traub, 2002a). In addition, colonic inflammation selectively increases the response of SUSTAINED neurons to CRD but has minimal effect on ABRUPT neurons (Ness and Gebhart, 2000). These data suggest that ABRUPT and SUSTAINED neurons are functionally distinct (but see Olivar et al., 2000). In the present study, the facilitatory effect of estrogen was observed solely in the ABRUPT neurons; SUSTAINED neurons were not affected by estrogen. The reason for the differential effect of estrogen on the two populations of CRD-responsive neurons is not clear. It is tempting to speculate that estrogen receptors are localized preferentially within an excitatory circuit activating ABRUPT, but not SUSTAINED, neurons. Alternatively, if estrogen receptors are confined or mainly colocalized to inhibitory interneurons (Amandusson et al., 1996, 1999), a pattern of inhibition and disinhibition may differentially modulate ABRUPT and SUSTAINED neurons.

\section{Potential mechanisms}

There are several possible mechanisms to account for estrogen increasing colorectal sensitivity. Considerable evidence suggests that steroids modulate neuronal excitability through interaction with neurotransmitter receptors, including NMDA, nonNMDA, GABA, and opioid receptors (Majewska, 1992; Paul and Purdy, 1992; Gu and Moss, 1996; Micevych et al., 1997; Foy et al., 1999; Rupprecht and Holsboer, 1999). For example, both NMDA and non-NMDA receptors modulate the spinal responses to innocuous and noxious colonic stimuli in male rats (Zhai and
Traub, 1999; Ji and Traub, 2001, 2002a; Traub et al., 2002b). Studies in our laboratory show a rightward shift of the doseresponse curve to intrathecal administration of an NMDA receptor antagonist on the vmr in estrogen-treated rats compared with ovariectomized rats, suggesting enhanced NMDA receptor activity in the spinal cord in the presence of estrogen (Traub et al., 2002a). One hypothesis to account for the effect of estrogen in the spinal cord is direct activation of the protein tyrosine kinase Src, which phosphorylates the NMDA receptor, thereby increasing activity (Gazzaley et al., 1996; Woolley et al., 1997; Salter, 1998; Foy et al., 1999; Bi et al., 2000; Migliaccio et al., 2000; Ali and Salter, 2001; Migliaccio et al., 2002; Nilsen et al., 2002). Alternatively, estrogen may modulate descending inhibition on spinal dorsal horn neurons from the supraspinal sites or alter inhibitory processing in the spinal cord (Amandusson et al., 1996, 1999; VanderHorst et al., 2002). Estrogen also reportedly decreased the binding of NMDA and AMPA receptors in certain brain areas, such as the frontal cortex and the nucleus accumbens, which are involved in modulation of pain perception (Bushnell et al., 1999; Cyr et al., 2001; Magnusson and Martin, 2002). Short-term treatment with estrogen in ovariectomized rats also decreased the number of opioid binding sites in the brain, decreasing the analgesic effects of morphine (Berglund et al., 1988; Weiland and Wise, 1990; Ratka and Simpkins, 1991). Finally, lumbosacral dorsal root ganglion neurons are immunoreactive for estrogen receptor- $\alpha / \beta$ (McNeill et al., 1991; Sohrabji et al., 1994; Taleghany et al., 1999; Papka et al., 2001; Papka and Storey-Workley, 2002), and patch-clamp recording from trigeminal ganglion neurons suggests that estrogen treatment increases the excitability of trigeminal ganglion neurons (Flake and Gold, 2002). Determination of which of these mechanism(s) contribute to the present observations are currently underway.

In summary, the present behavioral and electrophysiological studies clearly demonstrate that estrogen has a significant role in modulating viscerosensitivity. The loss of gonadal hormones decreases sensitivity, and estrogen replacement leads to recovery and some hypersensitivity. The increase in the response of dorsal horn neurons implicates increased processing in the spinal cord sensory system. These data further suggest that alterations in sensory processing in the spinal cord mediated by estrogen may underlie symptoms of IBS.

\section{References}

Al-Chaer ED, Lawand NB, Westlund KN, Willis WD (1996) Pelvic visceral input into the nucleus gracilis is largely mediated by the postsynaptic dorsal column pathway. J Neurophysiol 76:2675-2690.

Ali DW, Salter MW (2001) NMDA receptor regulation by Src kinase signalling in excitatory synaptic transmission and plasticity. Curr Opin Neurobiol 11:336-342.

Amandusson A, Hermanson O, Blomqvist A (1995) Estrogen receptor-like immunoreactivity in the medullary and spinal dorsal horn of the female rat. Neurosci Lett 196:25-28.

Amandusson A, Hermanson O, Blomqvist A (1996) Colocalization of oestrogen receptor immunoreactivity and preproenkephalin mRNA expression to neurons in the superficial laminae of the spinal and medullary dorsal horn of rats. Eur J Neurosci 8:2440-2445.

Amandusson A, Hallbeck M, Hallbeck AL, Hermanson O, Blomqvist A (1999) Estrogen-induced alterations of spinal cord enkephalin gene expression. Pain 83:243-248.

Bereiter DA (2001) Sex differences in brainstem neural activation after injury to the TMJ region. Cells Tissues Organs 169:226-237.

Berglund LA, Derendorf H, Simpkins JW (1988) Desensitization of brain opiate receptor mechanisms by gonadal steroid treatments that stimulate luteinizing hormone secretion. Endocrinology 122:2718-2726.

Berkley KJ (1997) Sex differences in pain. Behav Brain Sci 20:371-380.

Bi R, Broutman G, Foy MR, Thompson RF, Baudry M (2000) The tyrosine 
kinase and mitogen-activated protein kinase pathways mediate multiple effects of estrogen in hippocampus. Proc Natl Acad Sci USA 97: 3602-3607.

Bradshaw H, Miller J, Ling QD, Malsnee K, Ruda MA (2000) Sex differences and phases of the estrous cycle alter the response of spinal cord dynorphin neurons to peripheral inflammation and hyperalgesia. Pain 85:93-99.

Bradshaw HB, Temple JL, Wood E, Berkley KJ (1999) Estrous variations in behavioral responses to vaginal and uterine distention in the rat. Pain 82:187-197.

Brown-Grant K, Exley D, Naftolin F (1970) Peripheral plasma oestradiol and luteinizing hormone concentrations during the oestrous cycle of the rat. J Endocrinol 48:295-296.

Bushnell MC, Duncan GH, Hofbauer RK, Ha B, Chen JI, Carrier B (1999) Pain perception: is there a role for primary somatosensory cortex? Proc Natl Acad Sci USA 96:7705-7709.

Butcher RL, Collins WE, Fugo NW (1974) Plasma concentration of LH, FSH, prolactin, progesterone and estradiol-17beta throughout the 4-day estrous cycle of the rat. Endocrinology 94:1704-1708.

Case AM, Reid RL (1998) Effects of the menstrual cycle on medical disorders. Arch Intern Med 158:1405-1412.

Cyr M, Ghribi O, Thibault C, Morissette M, Landry M, Di Paolo T (2001) Ovarian steroids and selective estrogen receptor modulators activity on rat brain NMDA and AMPA receptors. Brain Res Brain Res Rev $37: 153-161$.

Dao TT, LeResche L (2000) Gender differences in pain. J Orofac Pain 14:169-184.

Dao TT, Knight K, Ton-That V (1998) Modulation of myofascial pain by the reproductive hormones: a preliminary report. J Prosthet Dent 79:663-670.

Dawson-Basoa M, Gintzler AR (1998) Gestational and ovarian sex steroid antinociception: synergy between spinal kappa and delta opioid systems. Brain Res 794:61-67.

Dawson-Basoa ME, Gintzler AR (1996) Estrogen and progesterone activate spinal kappa-opiate receptor analgesic mechanisms. Pain 64:608-615.

Drury RA, Gold RM (1978) Differential effects of ovarian hormones on reactivity to electric footshock in the rat. Physiol Behav 20:187-191.

Dupon C, Kim MH (1973) Peripheral plasma levels of testosterone, androstenedione, and oestradiol during the rat oestrous cycle. J Endocrinol 59:653-654.

Fillingim RB, Edwards RR (2001) The association of hormone replacement therapy with experimental pain responses in postmenopausal women. Pain 92:229-234.

Fillingim RB, Ness TJ (2000) Sex-related hormonal influences on pain and analgesic responses. Neurosci Biobehav Rev 24:485-501.

Flake N, Gold MS (2002) Inflammation- and estrogen-induced changes in the excitability of sensory neurons innervating the temporomandibular joint. J Pain 3:26.

Forman LJ, Tingle V, Estilow S, Cater J (1989) The response to analgesia testing is affected by gonadal steroids in the rat. Life Sci 45:447-454.

Foy MR, Xu J, Xie X, Brinton RD, Thompson RF, Berger TW (1999) 17betaestradiol enhances NMDA receptor-mediated EPSPs and long-term potentiation. J Neurophysiol 81:925-929.

Freeman ME (1994) The neuroendocrine control of the ovarian cycle of the rat. In: The physiology of reproduction (Knobil E, Neill JD, eds), pp 613-658. New York: Raven.

Gazzaley AH, Weiland NG, McEwen BS, Morrison JH (1996) Differential regulation of NMDAR1 mRNA and protein by estradiol in the rat hippocampus. J Neurosci 16:6830-6838.

Giamberardino MA, Affaitati G, Valente R, Iezzi S, Vecchiet L (1997) Changes in visceral pain reactivity as a function of estrous cycle in female rats with artificial ureteral calculosis. Brain Res 774:234-238.

Gintzler AR, Bohan MC (1990) Pain thresholds are elevated during pseudopregnancy. Brain Res 507:312-316.

Gu Q, Moss RL (1996) 17 $\beta$-Estradiol potentiates kainate-induced currents via activation of the cAMP cascade. J Neurosci 16:3620-3629.

Holdcroft A, Sapsed-Byrne S, Ma D, Hammal D, Forsling ML (2000) Sex and oestrous cycle differences in visceromotor responses and vasopressin release in response to colonic distention in male and female rats anesthetized with halothane. Br J Anaesth 85:907-910.

Ji Y, Traub RJ (2001) Spinal NMDA receptors contribute to neuronal processing of acute noxious and nonnoxious colorectal stimulation in the rat. J Neurophysiol 86:1783-1791.
Ji Y, Traub RJ (2002a) Differential effects of spinal CNQX on two populations of dorsal horn neurons responding to colorectal distention in the rat. Pain 99:217-222.

Ji Y, Traub RJ (2002b) Effects of estrogen on behavioral and neuronal responses to colorectal distention. J Pain 3:34.

Kane SV, Sable K, Hanauer SB (1998) The menstrual cycle and its effect on inflammatory bowel disease and irritable bowel syndrome: a prevalence study. Am J Gastroenterol 93:1867-1872.

Kayser V, Berkley KJ, Keita H, Gautron M, Guilbaud G (1996) Estrous and sex variations in vocalization thresholds to hindpaw and tail pressure stimulation in the rat. Brain Res 742:352-354.

LeResche L, Saunders K, Von Korff MR, Barlow W, Dworkin SF (1997) Use of exogenous hormones and risk of temporomandibular disorder pain. Pain 69:153-160.

Magnusson JE, Martin RV (2002) Additional evidence for the involvement of the basal ganglia in formalin-induced nociception: the role of the nucleus accumbens. Brain Res 942:128-132.

Majewska MD (1992) Neurosteroids: endogenous bimodal modulators of the GABAA receptor. Mechanism of action and physiological significance. Prog Neurobiol 38:379-395.

Martinez-Gomez M, Cruz Y, Salas M, Hudson R, Pacheco P (1994) Assessing pain threshold in the rat: changes with estrus and time of day. Physiol Behav 55:651-657.

Mathias JR, Clench MH, Reeves-Darby VG, Fox LM, Hsu PH, Roberts PH, Smith LL, Stiglich NJ (1994) Effect of leuprolide acetate in patients with moderate to severe functional bowel disease. Double-blind, placebocontrolled study. Dig Dis Sci 39:1155-1162.

McNeill DL, Sherburn EW, Galbraith JM, Klein CM, Westermeyer MM, Pilcher BK, Shew RL, Papka RE (1991) Effects of MK-801 on rat primary afferent neurons and fibers. Brain Res Bull 27:41-45.

Medina VM, Dawson-Basoa ME, Gintzler AR (1993) 17 beta-estradiol and progesterone positively modulate spinal cord dynorphin: relevance to the analgesia of pregnancy. Neuroendocrinology 58:310-315.

Mertz H, Naliboff B, Munakata J, Niazi N, Mayer EA (1995) Altered rectal perception is a biological marker of patients with irritable bowel syndrome. Gastroenterology 109:40-52.

Micevych PE, Eckersell CB, Brecha N, Holland KL (1997) Estrogen modulation of opioid and cholecystokinin systems in the limbic-hypothalamic circuit. Brain Res Bull 44:335-343.

Migliaccio A, Castoria G, Di Domenico M, De Falco A, Bilancio A, Lombardi M, Barone MV, Ametrano D, Zannini MS, Abbondanza C, Auricchio F (2000) Steroid-induced androgen receptor-oestradiol receptor beta-Src complex triggers prostate cancer cell proliferation. EMBO J 19:5406-5417.

Migliaccio A, Castoria G, Di Domenico M, De Falco A, Bilancio A, Auricchio F (2002) Src is an initial target of sex steroid hormone action. Ann NY Acad Sci 963:185-190.

Moore J, Barlow D, Jewell D, Kennedy S (1998) Do gastrointestinal symptoms vary with the menstrual cycle? Br J Obstet Gynaecol 105:1322-1325.

Munakata J, Naliboff B, Harraf F, Kodner A, Lembo T, Chang L, Silverman DH, Mayer EA (1997) Repetitive sigmoid stimulation induces rectal hyperalgesia in patients with irritable bowel syndrome. Gastroenterology [Erratum (1997) 113:1054] 112:55-63.

Ness TJ, Gebhart GF (1988) Colorectal distention as a noxious visceral stimulus: physiologic and pharmacologic characterization of pseudaffective responses in the rat. Brain Res 450:153-169.

Ness TJ, Gebhart GF (1989) Differential effects of morphine and clonidine on visceral and cutaneous spinal nociceptive transmission in the rat. J Neurophysiol 62:220-230.

Ness TJ, Gebhart GF (2000) Acute inflammation differentially alters the activity of two classes of rat spinal visceral nociceptive neurons. Neurosci Lett 281:131-134.

Ness TJ, Metcalf AM, Gebhart GF (1990) A psychophysiological study in humans using phasic colonic distention as a noxious visceral stimulus. Pain 43:377-386.

Nilsen J, Chen S, Brinton RD (2002) Dual action of estrogen on glutamateinduced calcium signaling: mechanisms requiring interaction between estrogen receptors and src/mitogen activated protein kinase pathway. Brain Res 930:216-234.

Olivar T, Cervero F, Laird JM (2000) Responses of rat spinal neurones to natural and electrical stimulation of colonic afferents: effect of inflammation. Brain Res 866:168-177.

Papka RE, Storey-Workley M (2002) Estrogen receptor-alpha and -beta co- 
exist in a subpopulation of sensory neurons of female rat dorsal root ganglia. Neurosci Lett 319:71-74.

Papka RE, Storey-Workley M, Shughrue PJ, Merchenthaler I, Collins JJ, Usip S, Saunders PT, Shupnik M (2001) Estrogen receptor-alpha and betaimmunoreactivity and mRNA in neurons of sensory and autonomic ganglia and spinal cord. Cell Tissue Res 304:193-214.

Paul SM, Purdy RH (1992) Neuroactive steroids. FASEB J 6:2311-2322.

Priest CA, Vink KL, Micevych PE (1995) Temporal regulation by estrogen of beta-preprotachykinin mRNA expression in the rat ventromedial nucleus of the hypothalamus. Brain Res Mol Brain Res 28:61-71.

Prior A, Stanley KM, Smith AR, Read NW (1992) Relation between hysterectomy and the irritable bowel: a prospective study. Gut 33:814-817.

Ratka A, Simpkins JW (1991) Effects of estradiol and progesterone on the sensitivity to pain and on morphine-induced antinociception in female rats. Horm Behav 25:217-228.

Ren K, Wei F, Dubner R, Murphy A, Hoffman GE (2000) Progesterone attenuates persistent inflammatory hyperalgesia in female rats: involvement of spinal NMDA receptor mechanisms. Brain Res 865:272-277.

Riley III JL, Robinson ME, Wise EA, Myers CD, Fillingim RB (1998) Sex differences in the perception of noxious experimental stimuli: a metaanalysis. Pain 74:181-187.

Ritchie J (1973) Pain from distention of the pelvic colon by inflating a balloon in the irritable colon syndrome. Gut 14:125-132.

Robbins A, Berkley KJ, Sato Y (1992) Estrous cycle variation of afferent fibers supplying reproductive organs in the female rat. Brain Res 596:353-356.

Rupprecht R, Holsboer F (1999) Neuroactive steroids: mechanisms of action and neuropsychopharmacological perspectives. Trends Neurosci 22:410-416.

Salter MW (1998) Src, $N$-methyl-D-aspartate (NMDA) receptors, and synaptic plasticity. Biochem Pharmacol 56:789-798.

Sapsed-Byrne S, Ma DQ, Ridout D, Holdcroft A (1996) Estrous cycle phase variations in visceromotor and cardiovascular responses to colonic distension in the anesthetized rat. Brain Res 742:10-16.

Sohrabji F, Miranda RC, Toran-Allerand CD (1994) Estrogen differentially regulates estrogen and nerve growth factor receptor mRNAs in adult sensory neurons. J Neurosci 14:459-471.

Taleghany N, Sarajari S, DonCarlos LL, Gollapudi L, Oblinger MM (1999) Differential expression of estrogen receptor alpha and beta in rat dorsal root ganglion neurons. J Neurosci Res 57:603-615.
Toner BB, Akman D (2000) Gender role and irritable bowel syndrome: literature review and hypothesis. Am J Gastroenterol 95:11-16.

Traub RJ, Ji Y, Kovalenko M (2002a) Estrogen alters sensitivity of the visceromotor reflex to NMDA receptor antagonists in the rat. IASP 10th World Congr Pain 287.

Traub RJ, Zhai QZ, Ji Y, Kovalenko M (2002b) NMDA receptor antagonists attenuate noxious and nonnoxious colorectal distention-induced Fos expression and the visceromotor reflex. Neuroscience 113:205-211.

Unruh AM (1996) Gender variations in clinical pain experience. Pain 65:123-167.

VanderHorst VG, Meijer E, Schasfoort FC, Van Leeuwen FW, Holstege G (1997) Estrogen receptor-immunoreactive neurons in the lumbosacral cord projecting to the periaqueductal gray in the ovariectomized female cat. Neurosci Lett 236:25-28.

VanderHorst VGJM, Meijer E, Holstege G (2001) Estrogen receptor- $\alpha$ immunoreactivity in parasympathetic preganglionic neurons innervating the bladder in the adult ovariectomized cat. Neurosci Lett 298:147-150.

VanderHorst VG, Terasawa E, Ralston III HJ (2002) Estrogen receptoralpha immunoreactive neurons in the ventrolateral periaqueductal gray receive monosynaptic input from the lumbosacral cord in the rhesus monkey. J Comp Neurol 443:27-42.

Weiland NG, Wise PM (1990) Estrogen and progesterone regulate opiate receptor densities in multiple brain regions. Endocrinology 126:804-808.

Williams SJ, Papka RE (1996) Estrogen receptor-immunoreactive neurons are present in the female rat lumbosacral spinal cord. J Neurosci Res 46:492-501.

Williams SJ, Chung K, Om AS, Papka RE (1997a) Cytosolic estrogen receptor concentrations in the lumbosacral spinal cord fluctuate during the estrous cycle. Life Sci 61:2551-2559.

Williams TL, Day NC, Ince PG, Kamboj RK, Shaw PJ (1997b) Calciumpermeable alpha-amino-3-hydroxy-5-methyl-4-isoxazole propionic acid receptors: a molecular determinant of selective vulnerability in amyotrophic lateral sclerosis. Ann Neurol 42:200-207.

Woolley CS, Weiland NG, McEwen BS, Schwartzkroin PA (1997) Estradiol increases the sensitivity of hippocampal CA1 pyramidal cells to NMDA receptor-mediated synaptic input: correlation with dendritic spine density. J Neurosci 17:1848-1859.

Zhai QZ, Traub RJ (1999) The NMDA receptor antagonist MK-801 attenuates c-Fos expression in the lumbosacral spinal cord following repetitive noxious and nonnoxious colorectal distention. Pain 83:321-329. 